Revue bibliographique pour le domaine irano-aryen

\title{
Mihaela Timuş. « Reléguer crânement l'adversaire aux enfers. Polémique antimanichéenne en terre mazdéenne »
}

Samra Azarnouche

\section{OpenEdition}

1 Journals

\section{Édition électronique}

URL : https://journals.openedition.org/abstractairanica/54052

DOI : 10.4000/abstractairanica.54052

ISSN : 1961-960X

Éditeur :

CNRS (UMR 7528 Mondes iraniens et indiens), Éditions de l'IFRI

\section{Référence électronique}

Samra Azarnouche, « Mihaela Timuş. "Reléguer crânement l'adversaire aux enfers. Polémique antimanichéenne en terre mazdéenne » », Abstracta Iranica [En ligne], Volume 42-43| 2021, document 13, mis en ligne le 30 décembre 2021, consulté le 14 décembre 2022. URL : http:// journals.openedition.org/abstractairanica/54052 ; DOI : https://doi.org/10.4000/abstractairanica 54052

Ce document a été généré automatiquement le 14 décembre 2022.

Tous droits réservés 


\title{
Mihaela Timuş. « Reléguer crânement l'adversaire aux enfers. Polémique antimanichéenne en terre mazdéenne »
}

\author{
Samra Azarnouche
}

\section{RÉFÉRENCE}

Mihaela Timuş. « Reléguer crânement l'adversaire aux enfers. Polémique antimanichéenne en terre mazdéenne » in Flavia Ruani, Mihaela Timuș (eds.). Quand les dualistes polémiquaient. Zoroastriens et manichéens. Leuven-Paris-Bristol: Peeters (Orient et Méditerranée 34), 2020, p. 125-154.

1 L'article revient sur les polémiques antimanichéennes du traité zoroastrien Škand Gūmānīg Wizār en y appliquant une grille de lecture formaliste et dégage les " opérations » que le polémiste zoroastrien pratique sur la figure de Mani et sa doctrine : l'usage d'un vocabulaire se réfèrent au monde infernal, en particulier dans le qualificatif de Mani (rad-mastarg " au cerveau fêlé » retraduis ici hypothétiquement par «maître (des) crâne(s)»), et le recourt à un substrat hérésiologique syriaque par l'auteur zoroastrien du traité, probablement via des traductions arabes, notamment pour le traitement du mythe manichéen de la séduction des archontes. 


\section{AUTEURS}

SAMRA AZARNOUCHE

EPHE, CeRMI, Paris 